\title{
AÇÃO POPULAR: UM INSTRUMENTO DEMOCRÁTICO E DE SOBERANIA POPULAR
}

Luiz Carlos de SOUZA JUNIOR*

\begin{abstract}
${ }^{*}$ Mestrando em Direito Constitucional pela Faculdade de Direito do Sul de Minas, Pouso Alegre, MG. Graduado em Direito pelo Centro Universitário Salesiano de São Paulo, U.E. Lorena. Graduado em Filosofia pela Universidade de Franca e especialista em Filosofia pela Faculdade Internacional Signorelli do Rio de Janeiro. Professor de Antropologia e História do Direito, Psicologia Jurídica, Projeto Integrador I (Empreendedorismo, Liderança, Criatividade e Inovação) e Projeto Integrador II (Responsabilidade Social, Educação, Étnico-racial) da graduação em Direito da Universidade Vale do Rio Verde (UninCor, unidade de Caxambu) e tutor da disciplina Pesquisa em Ensino da Filosofia da graduação em Filosofia da Universidade Federal de Lavras. E-mail: luizjuniorsdb@ hotmail.com.
\end{abstract}

Recebido em: 07/10/2015 - Aprovado em: 11/02/2016 - Disponibilizado em: 30/07/2016

\section{RESUMO:}

O presente artigo analisa o remédio constitucional da ação popular enquanto garantia constitucional política viabilizadora da participação democrática do cidadão na vida pública. Para consecução de tal intento utilizaremos o método analítico e a pesquisa bibliográfica. Explicitaremos os aspectos históricos da ação popular, a fim de possibilitar o entendimento das fases embrionárias através das quais foi possível atribuir ao povo, ou a parte dele, a legitimidade para pleitear a tutela jurisdicional de interesse coletivo. Faremos uma análise das bases do Estado Democrático de Direito a fim de realizar uma breve relação entre o regime democrático e a ação popular. E diante desta perspectiva, apresentaremos a ação popular como garantia constitucional política fortalecedora da democracia com a finalidade de fazer de todo cidadão um fiscal do bem comum. Assim, constataremos que a ação popular, embora seja desconhecida pelas mais variadas camadas sociais, de forma direta, se apresenta como sendo instrumento eficaz quando coroada pelos regimes democráticos, pois apenas dessa forma os interesses da coletividade podem ser protegidos.

PALAVRAS-CHAVE: Ação popular. Constituição Federal. Instrumento democrático. Democracia. Soberania popular.

\section{CLASS ACTION: A DEMOCRATIC INSTRUMENT AND POPULAR SOVEREIGNTY}

\begin{abstract}
:
This article analyses constitutional remedy of class action as a constitutional guarantee enabler policy of democratic citizen participation in public life. It will be explained historical aspects of class action in order to facilitate the understanding of the embryonic stages through which could be attributed to everybody, or part of it, the legitimacy to claim the judicial protection of collective interest. We will base the analysis democratic rule of law in order to conduct a brief relationship between democracy and popular action. On this perspective, we present the class action as a constitutional guarantee empowering political democracy in order to make every citizen a tax for the common good. This way, we will see that the class action, though unknown to the most varied social strata, directly, presents itself as an effective instrument when crowned by democratic regimes, because only this way the interests of the community can be protected.
\end{abstract}

KEYWORDS: Class action. Federal Constitution. Democratic instrument. Democracy. Popular sovereignty.

\section{INTRODUÇÃO}

À luz da Constituição Federal de 1988

a ação popular representa um remédio constitucional por meio do qual qualquer cidadão será investido de legitimidade com a finalidade de exercer um poder político, que decorre da soberania popular.

Desta maneira, tratamos por abordar a ação popular em relação ao próprio regime da 
democracia, haja vista que este instrumento configura-se como uma das formas de participação do cidadão na vida pública, exceto nos tempos durante os quais os regimes absolutistas reinaram.

Assim, a referida participação na vida pública pelo cidadão decorre de princípios democráticos, por meio dos quais este poder lhe é oferecido de modo originário.

A explicitação do tema em tela reforça a ideia da ação popular como garantia constitucional política, com vistas ao favorecimento do cidadão que, por meio desta mesma ação, tem a oportunidade de fiscalizar o desempenho das entidades em que o Estado tenha participação e/ou atos lesivos ao patrimônio público, à moralidade administrativa, ao meio ambiente e ao patrimônio histórico e cultural.

\section{ASPECTOS HISTÓRICOS}

Em busca de uma abordagem histórica a fim de visualizar os aspectos embrionários da ação popular, traçamos um parâmetro inicial analítico a partir das origens romanas.

$$
\text { O espírito cívico dos romanos }
$$
apontava para a necessidade de um cidadão dirigir-se ao magistrado para buscar a tutela de um bem, valor ou interesse que concernia não há ele diretamente, mas à coletividade.

Porém, a noção de "Estado" neste período da história do Direito não estava suficientemente delineado (MANCUSO, 2001, p. 39), pois a existência era de um robusto vínculo natural entre cidadão e a gens $^{l}$, , ou seja, o cidadão era envolto a um sentimento de que a res publica era "propriedade" dele próprio e que, por sua vez, se sentia legitimado a pleitear em juízo em nome da coletividade.

A actio romana exigia interesse pessoal e direto a ser exercido pelo próprio titular do direito, o cidadão perseguia uma finalidade caracterizada pelo altruísmo em defesa dos valores e bens louváveis.

Os bens que se destinavam ao uso comum, tais como os lagos e praças, eram, para os cidadãos romanos, como uma universalidade indivisa, na qual estavam inerentes, outrossim, o cidadão e o incipiente Estado. Tal concepção pode ser entendida como os primeiros delineamentos do que atualmente chamamos de interesse individual e interesse público.

Neste sentido, quando o cidadão agia de acordo com seu interesse particular, ele assegurava os direitos da coletividade. Posteriormente, o pretor estendeu este entendimento a dois outros aspectos: permitia particulares agirem mesmo nos casos de falta de interesse pessoal; e "substituiu os

\footnotetext{
1 "A palavra gens exprime exatamente o mesmo que genus, ambas correspondendo ao verbo gignere, e ao substantivo genitor, todas trazendo a ideia de filiação. Os Romanos, fora de dúvida, ligavam à palavra gens a ideia de uma origem comum" (TAVARES, 2006, p. 92).
} 
interditos por meios mais diretos" (MAGALHÃES, 1996, p. 221).

A maior parte das ações populares romanas possuía natureza penal, que acarretava em pena pecuniária, embora muitas objetivassem realizar atividade de polícia e outras traziam semelhança com as modernas ações cominatórias ou aos interditos proibitórios. Assim, havendo as ações populares penais e as civis (MAGALHÃES, 1996, p. 390).

Já durante o período da Idade Média, por força dos regimes absolutistas, não houve o cultivo das ações populares. Por isso, Nélson Carneiro afirma:

“A Idade Média não
cultivou as ações
populares, flores exóticas
nos regimes absolutos, e
cuja eficácia somente se
compreende (...) naqueles
em que cada cidadão se
preocupa pelas coisas
públicas como por seus
próprios negócios"
(CARNEIRO, 2015).

Dessa forma, as ações em tela se fazem presentes após as trevas do despotismo, por meio do ressurgimento dos Estados liberais.

No contexto moderno a ação popular ressurgiu na Bélgica, por meio da lei comunal de 30 de março de 1836 e logo após na França, por força da lei comunal de 18 de julho de 1837. Posteriormente na Itália houve a possibilidade de ações populares em matéria eleitoral, para impugnar isenções indevidas ou de beneficência pública (MANCUSO, 2001, p. 46). Há de se ressaltar que na referida península - da mesma forma que aconteceu no Brasil, no Estado Novo - a ação popular foi suprimida devido o regime fascista.

Em tempos contemporâneos, diante das necessidades do século XX, cabe ressaltar a ação popular em matéria penal, instituída na Espanha por meio da Ley de Enjuiciamiento Criminal, artigo 101.

$\mathrm{Na}$ esfera jurídica brasileira podemos observar o "divisor de águas" que representou a Constituição Federal de 1934, pois esta foi a primeira Constituição que deu guarida à ação popular no Capítulo II, "Dos Direitos e das Garantias Individuais", artigo 113, $§ 38$ : “qualquer cidadão será parte legítima para pleitear a declaração de nulidade ou anulação dos atos lesivos do patrimônio da União, dos Estados e dos Municípios" (BRASIL, 2015). Recordamos, ainda, que na Constituição Imperial de 1824, o artigo 157 tratava de certo somente de caráter disciplinar ou mesmo penal.

Na Constituição de 1937 não houve previsão legal. Porém, em 1946, após a derrocada do regime ditador, a ação popular foi reintroduzida no cenário jurídicoconstitucional, com a sensível ampliação de seu objeto, abarcando também a administração indireta: autarquias e sociedades de economia mista, sendo previsão presente também nas Cartas Magnas subsequentes. A Emenda Constitucional 1/69, 
em seu artigo 153, § 31, manteve a redação antes prevista na Carta de 1967.

Na Magna Carta de 1988 temos a vigência do inciso LXXIII do artigo $5^{\circ}$, no qual se optou por um critério analítico e abrangente (MANCUSO, 2001, p. 59), além da presença da natureza impessoal do interesse defendido por meio dela: o interesse da coletividade. Mais adiante abordaremos o tratamento jurídico à ação popular no ordenamento jurídico pátrio na atualidade.

Tendo por base os delineamentos históricos apontados anteriormente, apresentamos a seguinte esquematização da evolução histórica da ação popular no Constitucionalismo Brasileiro, almejando maior esclarecimento sobre a temática a partir da apresentação dos textos constitucionais in verbis:

\begin{tabular}{|l|lrl|}
\hline DISPOSITIVO & \multicolumn{3}{|c|}{ CONTEÚDO/ } \\
CARACTERÍSTICA
\end{tabular}

\begin{tabular}{|c|c|}
\hline & $\begin{array}{l}\text { Estados, dos Municípios, das } \\
\text { entidades autárquicas e das } \\
\text { sociedades de economia } \\
\text { mista". }\end{array}$ \\
\hline $\begin{array}{l}\text { Constituição } \\
\text { de } 1967 \text { (art. } \\
150, \S 31 \text { ) }\end{array}$ & $\begin{array}{l}\text { "Qualquer cidadão será parte } \\
\text { legítima para propor ação } \\
\text { popular que vise anular atos } \\
\text { lesivos ao patrimônio de } \\
\text { entidades públicas". }\end{array}$ \\
\hline 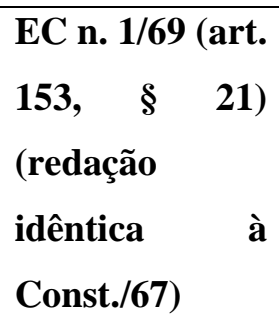 & $\begin{array}{l}\text { "Qualquer cidadão será parte } \\
\text { legítima para propor ação } \\
\text { popular que vise anular atos } \\
\text { lesivos ao patrimônio de } \\
\text { entidades públicas". }\end{array}$ \\
\hline $\begin{array}{l}\text { Constituição } \\
\text { de } 1988 \text { (art. } \\
5^{\circ}, \quad \text { LXXIII) } \\
\text { (ampliação de } \\
\text { seu objeto). }\end{array}$ & $\begin{array}{l}\text { "Qualquer cidadão será parte } \\
\text { legítima para propor ação } \\
\text { popular que vise anular ato } \\
\text { lesivo ao patrimônio público } \\
\text { ou de entidade de que o Estado } \\
\text { participe, à moralidade } \\
\text { administrativa, ao meio } \\
\text { ambiente e ao patrimônio } \\
\text { histórico e cultural, ficando o } \\
\text { autor, salvo comprovada má-fé, } \\
\text { isento de custas judiciais e do } \\
\text { onus da sucumbência" (cf. Lei } \\
\text { n. 4.717, de 29.06.1965). }\end{array}$ \\
\hline
\end{tabular}

Em consonância à temática ora proposta, cabe dar ênfase, diante das abordagens históricas apresentadas, à ausência da ação popular durante a vigência dos regimes autoritários, que nos levam a compreender que, de fato, a ação popular precisa do arejamento dos regimes democráticos e do clarão da luminosidade que 
resplandece do respeito às liberdades dos indivíduos.

\section{O ESTADO DEMOCRÁTICO DE DIREITO}

O apego à Constituição é característica presente na estrutura do Estado Democrático de Direito, haja vista que se trata da ordem jurídica fundamental, superior e oriunda da vontade popular, onde se vinculam os poderes como um todo e "seus atos e garantias de uma livre atuação das regras da jurisdição constitucional" (FURTADO, 1997, p. 23).

Segundo Norberto Bobbio "a democracia é a sociedade dos cidadãos, e os súditos se tornam cidadãos quando lhes são reconhecidos alguns direitos fundamentais" (BOBBIO, 2004, p. 27).

Com isso, podemos afirmar que os direitos fundamentais estabelecem uma fundamentação que não é meta-positiva, mas encontra-se positivada. Assim, os direitos fundamentais são situações jurídicas que foram estatuídas pelo direito positivo vigente, assegurando a liberdade, a igualdade e a fraternidade do ser humano.

Neste sentido, o constituinte de 1988 reconheceu a qualquer cidadão a utilização da ação popular com a finalidade de assegurar um direito fundamental de caráter coletivo.

Outrossim, a Constituição Brasileira de 1988, assenta a República em um Estado

Democrático de Direito, em seu artigo $1^{\circ}$, positivando os valores da democracia sobre os elementos que constituem o Estado, bem como sobre a ordem jurídica, robustecendo a participação popular, ajustando-se ao interesse coletivo.

De acordo com José Afonso da Silva, os direitos fundamentais se configuram como "direitos constitucionais na medida em que se inserem no texto de uma constituição ou mesmo constem de simples declaração solenemente estabelecida pelo poder constituinte" (SILVA, 2015, p. 123). Portanto, se fundamentam e se originam no princípio da soberania popular.

Dessa maneira, cabe ressaltar que a ação popular foi batizada como "essência da democracia" por Nélson Carneiro, ao relatar o discurso do deputado Marques dos Reis no Plenário durante os trabalhos da Comissão Constitucional para a edição da Constituição de 1934:

"Se, efetivamente, estamos
aqui organizando um
regime democrático; se
não somos daqueles que
acreditam que esse regime
já faliu, e o inscrevemos
no preâmbulo da
Constituição, não é
possível, de modo algum,
deixar de dar ingresso a
essa possibilidade, a essa
franquia, por meio da qual
toda cidadão brasileiro será
parte legítima para
promover a declaração de
nulidade ou anulação de
um ato lesivo ao
patrimônio público"
(CARNEIRO, 2015).


Portanto, embora a democracia não seja um valor-fim, mas um meio e instrumento de realização de valores essenciais de convivência humana (SILVA, 2015 , p. 128) ela se traduz como um valor basilar na efetividade dos direitos fundamentais do homem. E a democracia utiliza técnicas diversas para concretizar seus princípios (como o da soberania popular, a participação direta ou indireta do povo no poder etc.), e dentre essas técnicas podemos citar a propositura da ação popular pelo cidadão.

À vista disso, a ação popular como instrumento democrático reforça a ideia de que toda democracia, para ser tal, reside na vontade popular no que diz respeito ao manancial e exercício do poder, em negação aos regimes autocráticos.

Desta maneira, a partir do posicionamento doutrinário de José Afonso da Silva, no seu Curso de Direito Constitucional Positivo, a ação popular se enquadra na perspectiva teórica do princípio participativo caracterizado pela participação direita e pessoal da cidadania na confecção dos atos de governo. Pois, “as primeiras manifestações da democracia participativa consistiram nos institutos de democracia semidireta, que combinavam instituições de participação direta com instituições de participação indireta" (SILVA, 2015, p. 113) onde se enquadra a ação popular.

\section{AÇÃO POPULAR: GARANTIA CONSTITUCIONAL DEMOCRÁTICA}

Uma vez traçados os elementos históricos e abordagem sobre o Estado Democrático de Direito, passamos a tratar do caráter constitucional da ação popular e alguns tratamentos específicos da Lei $n$. 4.717, de 29 de junho de 1965 (LAP).

O legislador constitucional previu a legitimidade do cidadão $^{2}$, ou seja, o eleitor que se encontra no gozo de seus direitos políticos. Trata-se de uma ação judicial, pois o cidadão invoca a atividade jurisdicional com a intenção de anular ato lesivo ao patrimônio público ou de entidade de que o Estado participe, à moralidade administrativa, ao meio ambiente e ao patrimônio histórico e cultural, podendo haver consequente condenação dos responsáveis e beneficiários do ato em perdas e danos (LAP 11).

O Ministério Público possui atividades diversificadas, como custos legis e agente impulsionador da fase probatória. Porém, nos casos de desistência do autor popular, o Parquet torna-se legitimado ativo subsidiário do autor.

A ação popular possui fins corretivos, porém, pode a lei possibilitar a suspensão da liminar do ato impugnado para prevenir a

\footnotetext{
2 Trata-se, inclusive, de matéria sumulada pelo Supremo Tribunal Federal, Súmula 365: "Pessoa jurídica não tem legitimidade para propor ação popular".
} 
lesão (LAP $5^{\circ}, \S 4^{\circ}$ ). Se a pretensão restar improcedente, o dispositivo constitucional prevê a isenção do autor popular de custas e honorários de advogado, exceto nos casos de comprovada má-fé. Tal isenção constitucional corrobora com a proposta democrática da ação popular, retirando do autor qualquer onerosidade, pois age pro populo, como membro de uma comunidade. Cabe ressaltar que "a lei infraconstitucional dispõe que a coisa julgada se opera secundum eventum litis, não se caracterizando se o pedido for julgado improcedente por falta ou deficiência de provas" (NERY JUNIOR, 2006, p. 127).

Por outro lado, apesar de atestar que, de fato, ação popular brasileira é, corretiva, devido ao seu objeto, Waldir Gomes Magalhães (MAGALHÃES, 1998, p. 288) faz a distinção entre ações populares preventivas, supletivas, subsidiárias e corretivas. Vejamos:

As preventivas seriam aquelas que se destinam à prevenção de dano público; com as supletivas o autor propõe a ação no lugar do titular, ou seja, há uma substituição do representante da entidade pública no exercício de direito a este cabível; ao passo nas subsidiárias o autor age de forma conjunta aos órgãos da entidade; e por fim, nas corretivas, o interesse de agir do autor popular está conexo com os da comunidade a qual ele pertence, em face aos administradores de entidades ou do patrimônio público, com a finalidade de submetê-los à previsão do texto legal e para pedir ressarcimento do dano que eventualmente tais administradores tenham produzido à entidade administradora.

A Lei n. 4.717, de 29 de junho de 1965 declara nulos os atos lesivos que forem viciados por incompetência, vício de forma, ilegalidade do objeto, inexistência dos motivos e desvio de finalidade (art. $2^{\circ}$ ), bem como alguns que expressamente enumera (art. $4^{\circ}$ ). Declara anuláveis os atos lesivos, “cujos vícios" não forem indicados.

Neste sentido, Ferreira Filho destaca que falta clareza neste quesito ("vícios"), por não ser tarefa fácil identificar outros vícios diferentes aos enumerados na lei como causa de nulidade, a não ser que haja o entendimento de que o vício seja compreendido como "os atos lesivos praticados com malícia, ou violação das boas normas de moral administrativa ainda que formalmente perfeitos" (FERREIRA FILHO, 2008, p. 328).

As regras de competência dependerão da origem do ato ou omissão a seres impugnados. Por exemplo: se o patrimônio lesado for da União, competente será a Justiça Federal (art. $5^{\circ}$ da lei). Quando o pleito interessar simultaneamente à União e a quaisquer outras pessoas ou entidade, será competente o juiz das causas da União, se houver; quando interessar simultaneamente ao Estado e ao Município, será competente o juiz das causas do Estado, se houver $\left(\S 2^{\circ}\right)$.

Por força do artigo $1^{\circ}$, parágrafo único da Constituição Brasileira, o poder emana do 
povo que o exerce por meio de seus representantes eleitos ou diretamente. Dessa forma, o entendimento de José Afonso da Silva é de que a ação popular seja uma garantia constitucional política (SILVA, 2015, p. 466). A ação popular pode ser elencada no rol das garantias coletivas e garantias políticas justamente pelo fato do autor popular, por meio de atividade jurisdicional, pretender a defesa da coisa pública e tutela de interesses coletivos. Por isso, o remédio constitucional em tela pode ser identificado como instrumento fortalecedor da democracia.

Em suma, trata-se de uma função exercida pelo cidadão com o escopo fiscalizador, haja vista que, em regra, referida função seja exercida pelos representantes das Casas Legislativas. Por isso, podemos constatar que o remédio constitucional trabalhado neste artigo nasce da necessidade de aprimoramento da defesa do interesse público e da moral administrativa, com a finalidade de fazer de todo cidadão um fiscal do bem comum (FERREIRA FILHO, 2008, p. $325)$.

\section{CONSIDERAÇÕES FINAIS}

Diante da presente análise, desvela-se a ação popular como um instrumento necessário e basilar à manutenção dos regimes democráticos, haja vista a relevância do seu objeto: a proteção à moralidade administrativa, do meio ambiente e do patrimônio histórico cultural.

A explicitação a respeito da ação popular trás à tona o quanto esse remédio constitucional é preponderante à ordem jurídica dos Estados Democráticos de Direito, pois fortalece a participação popular e tutela o interesse coletivo.

Porém, embora tenhamos a previsão de tão importante remédio constitucional as mais variadas camadas sociais desconhecem a possibilidade dessa participação, de forma direta. Necessário seria a "conscientização jurídico-política" do povo a fim que a cidadania não passe apenas de um conceito formal, mas de condição real de participação da vida política no país.

\section{REFERÊNCIAS BIBLIOGRÁFICAS}

BRASIL, Constituição da República dos Estados Unidos do Brasil (de 16 de julho de 1934). Disponível em http://www.planalto.gov.br/civil_03/Constitui cao/Constituicao34.htm. Acesso em 15 de setembro de 2015.

CARNEIRO, Nélson. Das ações populares civis no direito brasileiro. Revista de Direito Administrativo 25/468. Fundação Getúlio Vargas. Disponível em http://bibliotecadigital.fgv.br/ojs/index.php/rd a/article/view/12141/11061. Acesso em 10 de setembro de 2015 .

FERREIRA FILHO, Manuel Gonçalves.

Curso de Direito Constitucional. $34^{\mathrm{a}}$ ed. rev. e atual.. São Paulo: Saraiva, 2008, 326. 
MAGALHÃES, Waldir Gomes. A ação popular. Cadernos de Direito Constitucional e Ciência Política, n. 14, jan.-mar. 1996.

MANCUSO, Rodolfo de Camargo. Ação Popular: proteção do erário, do patrimônio público, da moralidade administrativa e do meio ambiente. $4^{\mathrm{a}}$ ed. rev., atual. e ampl. São Paulo: Editora Revista dos Tribunais, 2001.

NERY JUNIOR, Nelson; NERY, Rosa Maria de. Constituição Federal Comentada e legislação constitucional. São Paulo: Revista dos Tribunais, 2006.

TAVARES, André Ramos. Curso de direito constitucional. $3^{\text {a }}$ ed. São Paulo: Saraiva, 2006.

SILVA, José Afonso da. Curso de Direito

Constitucional Positivo. $38^{\circ}$ ed., rev., atual.. Malheiros: São Paulo, 2015, p. 466.

Supremo Tribunal Federal. Súmula 365. Disponível em:

http://www.stf.jus.br/portal/jurisprudencia/list arJurisprudencia.asp?s1=s1=365.NUME. $\% 20$ NAO\%20S.FLSV.\&base $=$ baseSumulas .

Acesso em 15 de setembro de 2015.

FURTADO, Luísa Elisabeth Timbó Corrêa. Ação popular: mecanismo de controle dos atos da administração pública pelo cidadão. São Paulo: LTr. 1997. 